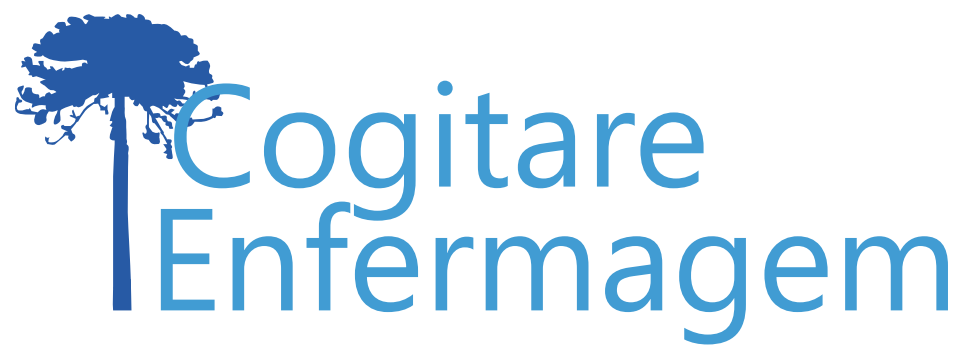

\title{
REFLEXÃO
}

\section{O CUIDADO POR PROFISSIONAIS NAS PRÁTICAS DE SAÚDE EM OBSTETRÍCIA À LUZ DE AYRES E BUBER*}

\author{
Patrícia Santos Oliveira', Telmara Menezes Couto², Keury Thaisana Rodrigues dos Santos Lima ${ }^{3}$, \\ Fanny Eichenberger Barral ${ }^{4}$, Aiara Nascimento Amaral Bomfim ${ }^{5}$
}

\section{RESUMO}

Objetivou-se discorrer uma reflexão sobre o cuidado às mulheres no processo de parto. Para tanto, utilizamos referenciais teóricos sustentados no cuidado fundamentado em Ayres e os pressupostos da existencialidade do ser por Buber. O cuidado na relação com o outro, nas práticas de saúde, em especial no campo da obstetrícia, diz respeito à capacidade de criar interações entre profissional de saúde e mulher no processo de parto associando o aspecto técnico e humanístico. Compreender as concepções teóricas sobre a relação entre profissionais e parturientes no cuidado em saúde é necessário para a reafirmação do paradigma de humanização e do cuidado no processo de parto. Esta reflexão contribui para reorientação do modelo assistencial de saúde focado em práticas humanizadas, com apoio nas evidências científicas e valorização das práticas de saúde fundamentadas no cuidado às mulheres no processo de parto.

DESCRITORES: Pessoal de Saúde; Enfermagem Obstétrica; Parto; Gestantes; Mulheres.

\footnotetext{
*Artigo extraído da dissertação de mestrado "Cuidado às mulheres no processo de parto: concepções de enfermeiras obstétricas". Universidade Federal da Bahia, 2018.
}

COMO REFERENCIAR ESTE ARTIGO:

Oliveira OS, Couto TM, Lima KTR dos S, Barral FE, Aiara Nascimento Amaral Bomfim. O cuidado por profissionais nas práticas de saúde em obstetrícia à luz de Ayres e Buber. Cogitare enferm. [Internet]. 2019 [acesso em "colocar data de acesso, dia, mês abreviado e ano"]; 24. Disponível em: http://dx.doi.org/10.5380/ce.v24i0.59889.

Este obra está licenciado com uma Licença Creative Commons Atribuição 4.0 Internacional.

${ }^{1}$ Enfermeira. Doutoranda em Enfermagem e Saúde. Universidade Federal da Bahia. Salvador, BA, Brasil.

Enfermeira. Doutora em Enfermagem. Docente de Pós-Graduação em Enfermagem e Saúde da Universidade Federal da Bahia. Salvador, BA, Brasil. 9

${ }^{3}$ Enfermeira. Mestra em Enfermagem. Universidade Federal da Bahia. Salvador, BA, Brasil. (9)

${ }^{4}$ Enfermeira. Mestra em Enfermagem. Universidade Federal da Bahia. Salvador, BA, Brasil.

${ }^{5}$ Enfermeira. Mestra em Enfermagem. Universidade Federal da Bahia. Salvador, BA, Brasil. 


\title{
CARE OF PROFESSIONALS IN OBSTETRIC HEALTHCARE PRACTICES IN THE LIGHT OF AYRES AND BUBER
}

\begin{abstract}
The aim of this article was to develop a reflection about care given to women during childbirth. To this end, we used theoretical frameworks of care as understood by Ayres and the assumptions of the existentiality of being by Buber. Care in relationships with the other, in health practices, especially in obstetrics, regards the capacity of creating interactions between health professionals and women during childbirth, associating technical and humanistic aspects. Understanding the theoretical conceptions about the relationship between professionals and women in childbirth in the health care is necessary to reaffirm the paradigm of humanization and care in the process of childbirth. This reflection contributes to reorganizing the healthcare model focused on humanized practices, based on scientific evidence and the recognition of health practices based on caring for women during childbirth.
\end{abstract}

DESCRIPTORS: Health Personnel; Obstetric Nursing; Parturition; Pregnant Women; Women.

\section{CUIDADO DE PROFESIONALES EN PRÁCTICAS OBSTÉTRICAS DE SALUD A LA LUZ DE AYRES Y BUBER}

\begin{abstract}
RESUMEN
El objetivo fue discutir una reflexión sobre la atención a mujeres en proceso de parto. Para ello, utilizamos referenciales teóricos sustentados en el cuidado fundamentado en Ayres y los supuestos de la existencialidad del ser de Buber. La atención en la relación con el otro en las prácticas de salud, particularmente en el área obstétrica, hace referencia a la capacidad de crear interacciones entre profesionales de salud y la mujer en proceso de parto, asociando el aspecto técnico al humanístico. Comprender las concepciones teóricas sobre la relación entre profesionales y parturientas en la atención de salud resulta necesario para reafirmar el paradigma de humanización y atención en el proceso de parto. Esta reflexión contribuye a reorientar el modelo asistencial de salud enfocado en prácticas humanizadas, con respaldo en evidencias científicas y en valorizar las prácticas de salud en la atención de las mujeres en proceso de parto.
\end{abstract}

DESCRIPTORES: Personal de Salud; Enfermería Obstétrica; Parto; Mujeres Embarazadas; Mujeres. 
O cuidado nas práticas de saúde é amplo por envolver diversos aspectos singulares do ser humano. Deste modo, o cuidado molda-se conforme as características apresentadas pela pessoa, e carece do estabelecimento da interação entre a(o) profissional de saúde e o indivíduo configurando-se em relacionamentos terapêuticos ${ }^{(1-2)}$.

O cuidado em saúde, em especial aquele prestado à mulher em processo de parto, comporta características de ser amplo e singular, permeado por significados relacionados ao desvelo, solicitude, diligência, zelo e atenção ${ }^{(3)}$. Este, por sua vez, tem contribuído para valorização das relações interpessoais, superando a visão meramente individualista, a qual foi construída dentro das práticas profissionais influenciadas por modelos de saúde tecnocratas. Trata-se, portanto, de reconstruir valores em uma sociedade marcada por iniquidades, sofrimentos e diferenças. É na presença do outro alicerçado em elementos como o diálogo, a escuta, o olhar, que se pode valorizar e compreender a existência do outro(2,4-5).

Tais elementos são fundamentais nas relações interpessoais para o desenvolvimento do cuidado em saúde associando os aspectos técnico e humanístico. Assim, compreender mutuamente a(o)s participantes envolvida(o)s no cuidado é relevante para identificação das lacunas que inviabilizam novos conhecimentos ${ }^{(2)}$. A prática da Enfermagem Obstétrica colabora para a disseminação do cuidado como tecnologia relacional fundamental para o acompanhamento de mulheres no processo de parto, no desprendimento e abertura de ambas as pessoas envolvidas no cuidado e principalmente no foco da construção de compreensão da mulher conforme seu contexto social|(6).

\section{O CUIDADO NA RELAÇÃO COM O OUTRO NO PROCESSO DE PARTO À} LUZ DE AYRES E BUBER

Em muitos serviços de saúde, a(o)s profissionais podem se restringir às práticas assistências vinculadas ao uso das técnicas, controle, tratamento e recuperação da saúde da população. Esta realidade não se difere quando comparada ao cuidado prestado à mulher no processo de parto.

Neste processo, tem sido adotadas condutas obstétricas que se distanciam do conceito de cuidado de saúde proposto por Ayres ${ }^{(2)}$, o qual propõe o cuidado como dimensão existencial, em que o(a) profissional de saúde interage com o outro a partir da busca por um encontro desejante, para além do êxito técnico. Entende-se o cuidado como uma categoria que necessita de compreensão filosófica e atitude prática em meio às solicitações de intervenções terapêuticas.

Neste sentido, são realizadas analogias pelo autor em relação ao cuidado, no campo da saúde, e as concepções filosóficas da fenomenologia. Assim, agrega-se ao cuidado aspectos tais como movimento, interação, identidade e alteridade, plasticidade, projeto, desejo, temporalidade e responsabilidade. Tais aspectos são fundamentais para a compreensão sobre a disposição do cuidado e suas características.

A interação permite que o cuidado se modele diante as divergências entre os sujeitos e o meio em que se estabelece uma relação. A identidade e alteridade, por sua vez, acontecem mediante a existência da interação. Desde modo, as identidades existenciais se concretizam no momento da construção da interação frente à presença do outro, e consequentemente a alteridade é revelada, permitindo a compreensão a partir da visão cultural alheia, fomentada na relação interpessoal ${ }^{(2,7)}$.

O cuidado está em movimento e se remodela de acordo com a construção de identidade e alteridade, definindo o aspecto da plasticidade. Esta propicia o indivíduo se 
projetar, participar do projeto de cuidado sobre si mesmo. O projeto só toma forma quando existe o desejo, o tomar para si imbricado no processo de cuidado, o qual depende de um fluxo temporal limitado a partir da coexistência de todos envolvidos.

Em análise de Ayres $^{(2)}$, o cuidado acarreta na existencialidade do ser mediante a construção de uma relação. Diante disso, cabe mencionar os pressupostos relacionados com algumas correntes da fenomenologia do filósofo Buber ${ }^{(5)}$, o qual enaltece as múltiplas possibilidades do existir do ser humano no mundo, entre o vivido e experienciado. Este autor prioriza conceitos centrais fundamentados nas relações existentes entre os seres humanos e a palavra como sendo dialógica.

Estes conceitos se sustentam na compreensão do homem, o qual pode assumir três possiblidades de relacionar e de existir por meio da palavra-princípio "EU-TU", "EUISSO" e o "EU-TU Eterno". O ser humano na relação "EU-TU" representa o encontro entre dois seres que estão dispostos de maneira recíproca e mútua para que o inter-humano desabroche a conversação genuína. Nesta perspectiva, o "EU" se, abre para o "TU", a pessoa se deixa levar pelo envolvimento da presença viva do outro. É nesse momento que o "EU" se revela para o "TU": quando se alcança o centro da pessoa permitindo o "entre" a partir da percepção do conhecimento sobre o outro, por meio da escuta real numa relação vivida e não pensada ${ }^{(5)}$.

Em paralelo à concepção de encontro com o outro, uma analogia pode ser atribuída ao acompanhamento de mulheres no processo de parto. Já que uma relação é constituída com a(o) profissional de saúde, a qual é demonstrada por meio do silêncio, da palavra, da linguagem não verbal, pois ao "TU", a mulher, é concedida a liberdade de expressão diante do encontro entre $\mathrm{a}(\mathrm{o})$ profissional e a mulher.

Vale destacar a existência da relação "EU-ISSO", que aborda o distanciamento do "TU", possibilitando ao ser humano experienciar de forma objetiva as situações vividas. Este tipo de relação tende a encarar as situações de maneira objetiva, contudo, é fundamental para a construção do saber, produção de significados e conhecimento acerca do mundo(8-10).

Assim, "EU-TU" e "EU-ISSO" são partes inseparáveis da existência humana sendo imprescindíveis nas relações, as quais necessitam ser estabelecidas a partir de interações em que as pessoas envolvidas participem sem desconsiderar a existência do outro, alternando as atitudes pautando-se no "EU-TU" e "EU-ISSO"(5,9).

Já o encontro do "EU-TU Eterno" é um momento puro e autêntico, pois o ser humano encontra a possibilidade de recuperar a essência do ser e buscar adentrar na relação com o outro. Trata-se de uma relação entre o homem e Deus, considerado em sua alteridade absoluta. Para tanto, deve-se considerar a maneira como o ser humano se relaciona com Deus ${ }^{(5)}$.

Nesta perspectiva buberiana, o cuidado às mulheres no processo de parto imprescinde do encontro entre profissional de saúde e a mulher. Tal encontro perpassa o diálogo, o uso da palavra, silêncio, linguagens não verbais que transcendem todo o momento no trabalho de parto e parto. Com a inserção do novo paradigma humanizado no cuidado à mulher no processo de parto, se faz importante a compreensão de concepções teóricas sobre a relação entre profissionais e parturiente no cuidado em saúde, respeitando o modo de ser da mulher nas práticas de saúde.

Ao cuidado é atribuída a parte humanística, que considera o querer, fazer projetos, moldar atitudes. Trata-se de refletir e reconstruir entre o técnico e o senso comum. E assumir uma atitude cuidadora no campo da saúde priorizando a intersubjetividade, assim a(o) profissional ao se colocar diante da(o) outro(a) se reconhece como sujeito participante a cada experiência de encontro. É valorizar o caráter relacional, e construir o "outro de cada um"(2,11).

O encontro entre profissional de saúde e mulher possibilita a ocorrência de projetos de felicidade, os quais são relevantes para orientar os projetos existenciais das mulheres 
no cuidado no processo de parto. Ayres ${ }^{(2)}$ define os "projetos de felicidade" como projetos que direcionam para as experiências vividas, valoradas positivamente, experiências estas que têm estreita relação entre experiência vivida, valor e aspirações, e que por sua vez são relevantes para a compreensão das situações existentes a partir das condições de vida humana na busca pela felicidade.

No processo do parto, é possível traçar projetos de felicidade, a partir dos anseios das parturientes que podem se tornar perceptíveis e factíveis pela interação construída entre profissional e mulher. Tal interação possibilita a compreensão das sensações bastante comuns nesse processo, como os desconfortos físicos, ansiedade, medo, angústias, dentre outras $^{(12)}$. É a possibilidade de participação da(o)s profissionais de enfermagem nos projetos de felicidade das mulheres no processo de parto, demonstrando a responsabilidade pelo cuidado e reafirmando a preocupação diante do outro no cotidiano das relações interpessoais.

\section{CONCLUSÃO}

O cuidado em saúde imprescinde de compreensão filosófica de suas bases bem como de atitudes que na prática possam se desvelar dentro do contexto de encontros entre profissionais e usuários. Para tanto é necessária a existência de movimento, interação, identidade e alteridade, plasticidade, projeto, desejo, temporalidade e responsabilidade nas práticas de saúde.

No processo de parto, o cuidado ofertado à mulher não é diferente, podendo se revelar como dimensão existencial, em que profissionais e mulheres consigam se colocar diante do outro em relação de existencialidade.

Compreender as concepções teóricas sobre a relação entre profissionais e parturiente no cuidado em saúde são pontes importantes para a reafirmação do paradigma de humanização e do próprio cuidado no processo de parto. É o cuidado humanístico que possibilita moldar atitudes, e permite a reflexão e reconstrução de práticas assistenciais que valorizem o ser humano e seus projetos de felicidade.

Esta reflexão contribui para críticas e pesquisas futuras que possibilitem a mudança de modelos de saúde centrados no cuidado meramente tecnocrata, e incitem futuras pesquisas científicas respaldadas na valorização das relações interpessoais com as mulheres no processo de parto.

\section{REFERÊNCIAS}

1. Percy $M$, Richardson $C$. Introducing nursing practice to student nurses: How can we promote care compassion and empathy. Nurse Educ Pract [Internet]. 2018 [acesso em 10 fev 2018]; 29(Suppl 1). Disponível em: https://doi.org/10.1016/j.nepr.2018.01.008.

2. Ayres JR de CM. Cuidado: trabalho, interação e saber nas práticas de saúde. Rev. baiana enferm. [Internet]. 2017 [acesso em 20 mar 2018]; 31(1). Disponível em: http://dx.doi.org/10.18471/rbe. v31i1.21847.

3. Souza ML de, Sartor VV de B, Padilha MI de CS, Prada ML do. O cuidado em enfermagem: uma aproximação teórica. Texto contexto-enferm. [Internet]. 2005 [acesso em 28 mar 2018]; 14(2). Disponível em: http://dx.doi.org/10.1590/S0104-07072005000200015.

4. Haley B, Heo S, Wright P, Barone C, Rettiganti MR, Anders M. Relationships among active listening, self-awareness, empathy, and patient-centered care in associate and baccalaureate degree nursing students. Nursin Plus Open. [Internet]. 2017 [acesso em 30 abr 2018]; 3(Suppl 1). Disponível em: https:// 
5. Buber M. Ee e Tu. Trad. de Newton Aquiles Von Zuben. 10. ed. São Paulo: Centauro; 2012.

6. Torres JA, Santos I dos, Vargens OM da C. Construindo uma concepção de tecnologia de cuidado de enfermagem obstétrica: estudo sociopoético. Texto contexto-enferm. [Internet]. 2008 [acesso em 05 mar 2018]; 17(4). Disponível em: http://dx.doi.org/10.1590/S0104-07072008000400005.

7. Scholze A da S, Duarte Junior CF, Flores e SilvaY. Trabalho em saúde e a implantação do acolhimento na atenção primária à saúde: afeto, empatia ou alteridade? Interface [Internet]. 2009 [acesso em 04 jan 2018]; 13(31). Disponível em: http://dx.doi.org/10.1590/S1414-32832009000400006.

8. Amatuzzi MM. O resgate da fala autêntica. Campinas: Alínea; 2016.

9. Luczinski GF, Ancona-Lopez M. A psicologia fenomenológica e a filosofia de Buber: o encontro na clínica. Estud. psicol. [Internet]. 2010 [acesso em 22 maio 2018]; 27(1). Disponível em: http://dx.doi. org/10.1590/S0103-166X2010000100009.

10 Schurich D, Crossetti M da GO. O elemento dialógico no cuidado de enfermagem: um ensaio com base em Martin Buber. Esc. Anna Nery [Internet]. 2008 [acesso em 13 maio 2018]; 12(3). Disponível em: http://dx.doi.org/10.1590/S1414-81452008000300022.

11 Gubert PG. A pequena ética de Paul Ricoeur. Impulso. [Internet]. 2014 [acesso em 15 maio 2018]; 24(59). Disponível em: http://dx.doi.org/10.15600/2236-9767/impulso.v24n59p81-91.

12. Silva ALS, Nascimento ER do, Coelho E de AC. Práticas de enfermeiras para promoção da dignificação, participação e autonomia de mulheres no parto normal. Esc. Anna Nery [Internet]. 2015 [acesso em 24 abr 2018]; 19(3). Disponível em: http://dx.doi.org/10.5935/1414-8145.20150056.

Recebido: $12 / 06 / 2018$

Finalizado: 07/06/2019

Autor Correspondente:

Aiara Nascimento Amaral Bomfim

Universidade Federal da Bahia

R. Basílio da Gama, 241 - 40110-100 - Salvador, BA, Brasil

E-mail: aiaraamaral@hotmail.com

Contribuição dos autores:

Contribuições substanciais para a concepção ou desenho do estudo; ou a aquisição, análise ou interpretação de dados do estudo - KTRSL

Elaboração e revisão crítica do conteúdo intelectual do estudo - FEB, ANAB

Aprovação da versão final do estudo a ser publicado - TMC

Responsável por todos os aspectos do estudo, assegurando as questões de precisão ou integridade de qualquer parte do estudo - PSO 